\title{
Geometric properties of projective constraint violation stabilization method for generally constrained multibody systems on manifolds
}

\author{
Zdravko Terze $\cdot$ Joris Naudet
}

Published online: 16 April 2008

(C) Springer Science+Business Media B.V. 2008

\section{Erratum to: Multibody Syst Dyn \\ DOI 10.1007/s11044-008-9107-5}

Errors are present in the second paragraph of Sect. 3 within the second and third sentences. The correct presentation of these sentences is given below.

The constraint matrix $\boldsymbol{\Phi}_{\mathbf{x}}^{*}(\mathbf{x}, t)$ can be written in the form $\boldsymbol{\Phi}_{\mathbf{x}}^{* \mathrm{~T}}(\mathbf{x}, t)=\left[\boldsymbol{\varphi}_{1}^{*}, \ldots, \boldsymbol{\varphi}_{r}^{*}\right]$, where, for example, $\boldsymbol{\varphi}_{1}^{*}=\left[\varphi_{1 i}\right]$ is given as $\hat{\boldsymbol{\varphi}}_{1}=\varphi_{1 i} \hat{\mathbf{g}}_{\mathbf{x}}^{i}$. The vectors $\hat{\boldsymbol{\varphi}}_{1}, \ldots, \hat{\boldsymbol{\varphi}}_{r}$ represent gradients to constraint "hyper-surfaces" determined in the configuration space by the equations $\boldsymbol{\Phi}(\mathbf{x}, t)=\mathbf{0}$, i.e., $\hat{\boldsymbol{\varphi}}_{1}=\operatorname{grad} \Phi_{1}, \ldots, \hat{\boldsymbol{\varphi}}_{r}=\operatorname{grad} \Phi_{r}$.

The online version of the original article can be found under doi:10.1007/s11044-008-9107-5.

\section{Z. Terze $(\bowtie)$}

Department of Aeronautical Engineering, Faculty of Mechanical Engineering and Naval Architecture, University of Zagreb, Ivana Lucica 5, 1000 Zagreb, Croatia

e-mail: zdravko.terze@fsb.hr

\section{J. Naudet}

Department of Mechanical Engineering, Multibody Mechanics Group, Vrije Universiteit Brussel,

Brussels, Belgium 